\title{
Socioeconomical conditions as risk factors for bronchial asthma in children aged 4-5 yrs
}

\author{
M. Lindbæk*, K.W. Wefring", E.H. Grangård" ${ }^{\#}$ K. Øvsthus
}

Socioeconomical conditions as risk factors for bronchial asthma in children aged 4-5 yrs. M. Lindbak, K.W. Wefring, E.H. Grangård, K.Øvsthus. (C) ERS Journals Ltd 2003. ABSTRACT: A number of factors are associated with the development of childhood asthma. The purpose of this study was to establish the prevalence of childhood asthma and to explore the socioeconomic background factors associated with childhood asthma in a Norwegian cohort of children aged 4-5 yrs.

A questionnaire was given to parents in connection with the ordinary child control of 4-5-yr-old children in Vestfold county, Norway. In addition to the question "Has the child at present or ever had asthma?", a number of medical and socioeconomical background factors were registered.

Of the 2,430 parents, $1,913(79 \%)$ responded. Of the 163 (cumulative prevalence $8.7 \%$ ) children with confirmed asthma, 19 did not use any medication and were regarded as having outgrown their asthma. Several background factors were significantly associated with asthma in a logistic regression analysis: few rooms at home, psychosocial problems, fever more than three times during the last year, hay fever, reaction to food and mother or father with chronic disease.

The findings indicate that socioeconomic background factors are associated with asthma in childhood, in addition to other known risk factors. Eur Respir J 2003; 21: 105-108.
* Dept of General Practice and Community Medicine, University of Oslo, Oslo, ${ }^{\#}$ Dept of Paediatrics, Vestfold Central Hospital, Vestfold and "The District Physician Office, Tjøme, Norway.

Correspondence: M. Lindbæk, Dept of General Practice and Community Medicine, PO Box 1130 Blindern, $\mathrm{N}-0317$ Oslo, Norway. Fax: 4722850650

E-mail: morten.lindbak@samfunnsmed. uio.no

Keywords: Asthma, childhood, risk factor, socioeconomic

Received: May 22001

Accepted after revision: January 18 2002
There is a worldwide trend of increasing asthma prevalence $[1,2]$, with large international variations [2]. A number of studies have been undertaken to try to explain the variations and to detect risk factors for the development of childhood asthma. The risk factors that have been found can be subdivided in many ways; in this study they were divided into medical and socioeconomical factors. Among those first mentioned, the most consistent ones have been allergy [3], eczema [4], antibiotic use [5], reactions to food [6], early respiratory syncytial virus infection [7] and parental asthma [8]. Breastfeeding has also been considered to give protection against childhood asthma $[8,9]$. Young males have been found to have a higher risk of asthma than young females [3].

Among the socioeconomical factors, indoor smoking has been the most consistent risk factor [10]. Conflicting data have been found in the evaluation of socioeconomical factors, such as family income and parental education $[8,11]$. In a study from New Zealand, there was no risk of asthma associated with the structure, practice and dynamics of the child's family [11]. A previous Norwegian study concluded that childhood asthma was associated with low socioeconomical status [12]. Conflicting data have also been found concerning children in day care centres. In one study, day care attendance was found to protect children against allergy [13], but in a recent Norwegian study, this was associated with a higher risk of asthma [14]. The purpose of this study was to establish the prevalence of and possible risk factors for asthma in a large cohort of Norwegian children 4-5 yrs of age with the diagnosis confirmed by a doctor.

\section{Methods and materials}

In connection with the ordinary public health control of children aged 4 yrs in the Vestfold county (South-East Norway), parents were requested to answer an extensive questionnaire concerning the child's health, the prevalence of chronic diseases and the family in general. The study was started in April 1995 and was terminated $1 \mathrm{yr}$ later. The questionnaires were distributed through the community health stations. The idea was to investigate all children born in 1991 (the 4-yr cohort=2,491), but due to practical limitations, some children born in 1992 also had to be included. The total number included was very close to a 1 -yr cohort.

The parents were asked whether the child was suffering from bronchial asthma at present, or had done so previously, and whether the diagnosis had been confirmed by a doctor. Other questions included the number of respiratory tract infections during the last year, the number of wheezing episodes in the last 12 months, the use of any medication during the last year, the length of breastfeeding during the first year of life, and if the child had ever had any eczema or any 
reactions to food or hay fever. In addition, the questionnaire included some socioeconomical background data, of which the interest areas included child day care attendance, number of rooms at home (divided into three equal groups), smoking during pregnancy and/or later, parental chronic disease, parental education, parents divorced or living with new partners, and the child's number of siblings.

Data were also collected from records of the routine medical control taken between the ages of 4-5 yrs at the community health station, including birth weight of the child, and the physical examination findings of their doctor. One of the standardised questions in these records was devoted to psychosocial problems in the family with the following alternative answers: no problems, problems noted but action unnecessary, problems noted and action necessary.

Parents who confirmed that their child had asthma or another chronic disease were asked to bring the child to an extra consultation at the health station, which included a structured interview undertaken by an experienced paediatrician. This interview included further questions about the diagnoses: whether they were confirmed by a doctor, which medication had been used the last year, and whether the parents were content with the primary medical care and the hospital service. All relevant information was also collected about the children who had been in contact with the Vestfold Central Hospital, Norway. This was necessary to validate the information given in the primary questionnaire and at the follow-up visit. In the validation of the final asthma diagnosis, the parents' responses to the questionnaire were used, including questions about asthma, other atopic disease, wheezing episodes and medication in the previous year, diagnosis confirmed by doctor, data from the follow-up consultation, and patient records from the hospital.

The questionnaires were anonymous. The data were analysed with the Chi-squared test and a level of 0.05 was considered significant. The risk factors for asthma were analysed through use of logistic regression with confirmed asthma as the dependent variable, including factors with a $\mathrm{p}<0.20$ in the bivariate analysis [15]. The study was approved by the Data Protection Agency and the Regional Ethics Committee.

\section{Results}

A total of 2,430 questionnaires were distributed and $1,913(79 \%)$ were answered by the parents. Of these, 1,884 replied to the question about asthma. Onehundred and seventy parents stated that their child had asthma at present or had previously suffered from it. Of the 170 parents, 107 with an asthmatic child came to the follow-up visit. The diagnosis could not be confirmed in seven of the children in the validation process, resulting in a cumulative prevalence of asthma of $8.7 \%$ of this $4-5$-yr-old cohort. Nineteen of the children had not used any asthma medication during the last year and were regarded as having outgrown their problems, resulting in an asthma point prevalence of $7.7 \%$ in this age group. Among those children whose parents answered "no" to asthma, 56 had more than three episodes of wheezing during the last year. Of these, 15 children used asthma medication, including antihistamines. In the validation process, they were not included in the asthma group, primarily due to short duration of medication during the last year.

The distribution of "yes" answers in the cohort to the medical and socioeconomical background data is presented in table 1 . Most of the questions were answered by $>95 \%$ of parents. Among the medical factors, a significantly higher proportion of children with confirmed asthma had experienced more than three episodes of fever during the last year, had suffered from eczema over a period of $\geqslant 4$ weeks during the last year, and had reaction to food or hay fever.

Among the socioeconomical factors, a significantly higher proportion of the asthmatic children had: less than five rooms at home; one parent with a chronic disease; divorced parents or parents living with a new partner; only one parent at home; and psychosocial problems in the family.

The relationship between psychosocial problems noted and poor control of asthma as indicated by hospitalisation during the last year was analysed. Of the children with psychosocial problems, $35 \%$ were hospitalised versus $14 \%$ of the children without such problems $(\mathrm{p}=0.01)$.

The results of the logistic regression analysis are presented in table 2, with confirmed asthma as the dependent variable, and independent variables with $\mathrm{p}<0.20$ in the bivariate analysis. The following factors were independently associated: more than three episodes of fever during the last year, hay fever, chronic disease in one or both of the parents, food reactions, psychosocial problems and less than five rooms in the home. Breastfeeding, day care attendance, sex, smoke exposure during pregnancy or later, or having no siblings showed no association with asthma. The number of siblings was analysed both as a dichotome variable and as a continuous variable.

\section{Discussion}

This study covers a representative cohort of children aged 4-5 yrs recruited from the public health station where all children meet for normal routine health control. The estimated prevalence of doctor-diagnosed asthma is representative for this age group in this part of Norway. A limitation of the study is caused by the fact that the asthma diagnosis was based primarily on parental information. However, the diagnoses were validated by data from other sources, such as medical records from the county hospital and the use of medication during the last year. The presence of asthma was confirmed in $95 \%$ of the cases. The cumulative prevalence of $8.7 \%$ is similar to previous Norwegian studies $[1,16]$.

Among the socioeconomical factors, chronic disease in either one of the parents, a low number of rooms in the home and psychosocial problems were independently associated with asthma. Although the 
Table 1. - Proportion of positive answers to questions about background factors in children aged 4-5 yrs with confirmed asthma $(n=163)$ and without asthma $(n=1721)$ in the county of Vestfold, Norway, 1996

\begin{tabular}{|c|c|c|c|c|}
\hline & Asthma & Not asthma & Answers $n$ & p-value \\
\hline \multicolumn{5}{|l|}{ Medical factors } \\
\hline Breastfeeding over 3 months & $152(93)$ & $1591(93)$ & 1881 & 0.67 \\
\hline Over three episodes of fever last year & $90(55)$ & $442(26)$ & 1835 & 0.00001 \\
\hline Eczema ever & $73(45)$ & $583(34)$ & 1858 & 0.007 \\
\hline Eczema over 4 weeks last year & $34(21)$ & $186(11)$ & 1689 & 0.00006 \\
\hline Use of antibiotic last year & $52(32)$ & $563(32)$ & 1884 & 0.67 \\
\hline Any reaction to food & 47 (29) & $193(11)$ & 1851 & 0.00001 \\
\hline Hay fever & $21(13)$ & $58(3)$ & 1837 & 0.00001 \\
\hline \multicolumn{5}{|l|}{ Socioeconomical factors } \\
\hline Day care attendance & $97(60)$ & $1028(59)$ & 1915 & 0.79 \\
\hline Proportion of boys & $90(55)$ & $853(50)$ & 1865 & 0.19 \\
\hline Less than five rooms at home & $71(44)$ & $593(35)$ & 1846 & 0.005 \\
\hline Daily smoking at home & $71(44)$ & $683(40)$ & 1859 & 0.59 \\
\hline Mother or father with chronic disease & $56(35)$ & $278(17)$ & 1884 & 0.0001 \\
\hline Father had higher education & $52(34)$ & $623(39)$ & 1733 & 0.18 \\
\hline Mother had higher education & $51(31)$ & $567(33)$ & 1861 & 0.67 \\
\hline Smoking during pregnancy & $45(27)$ & $353(21)$ & 1860 & 0.09 \\
\hline Parents divorced/new partner & $38(23)$ & $270(16)$ & 1858 & 0.008 \\
\hline No siblings & $35(21)$ & $287(17)$ & 1866 & 0.20 \\
\hline Single parent & $27(17)$ & $197(12)$ & 1861 & 0.05 \\
\hline Psychosocial problem, no action & $14(9)$ & $90(5)$ & 1716 & 0.07 \\
\hline Psychosocial problem, action needed & $9(6)$ & $22(1)$ & 1716 & 0.00001 \\
\hline
\end{tabular}

Data are presented as n (\%) unless otherwise stated.

Table 2. - Factors independently associated with confirmed asthma in 5-yr-old children by logistic regression

\begin{tabular}{lccc}
\hline Factor & Subjects n (\%) & OR (95\% CI) & p-value \\
\hline More than three episodes of fever last year & $491(29)$ & $3.03(2.11-4.37)$ & 0.00001 \\
Hay fever & $77(5)$ & $2.70(1.49-4.92)$ & 0.001 \\
Mother or father with chronic disease & $337(18)$ & $2.34(1.58-3.46)$ & 0.0001 \\
Any reaction to food & $220(13)$ & $2.10(1.33-3.32)$ & 0.0001 \\
Psychosocial problems in family & $1466(92)$ & 1.00 & \\
No problems (reference) & $93(6)$ & $3.33(1.31-8.49)$ & 0.23 \\
Problems, action not needed & $28(2)$ & 1.00 & 0.01 \\
Problems, action needed & $683(38)$ & $1.92(1.26-2.93)$ & 0.002 \\
Rooms in house & $615(36)$ & $1.36(0.84-2.20)$ & 0.22 \\
5-6 (reference) & $430(26)$ & \\
$<5$ & & & \\
$>6$ & & & \\
\hline
\end{tabular}

OR: odds ratio; CI: confidence interval. In total, 1587 of 1884 children are included in the regression analysis due to varying response to the different questions.

parents were not specifically asked about parental asthma, it seems reasonable to assume that asthma is one of the most frequent chronic diseases among the parents of children suffering from this inheritable condition [3], and that this might be the only explanation for the relationship found. Furthermore, the asthma group showed a tendency of lower parental educational level and a higher frequency of single parents. These findings may indicate that asthma is a low status disease in Norway. However, data regarding the families' incomes were lacking, and therefore, this hypothesis cannot be fully confirmed. It was previously reported that asthma in Norwegians was associated with low socioeconomical status, as expressed by the number of years of education, which is in agreement with the present study [12].

Conflicting data have been found in international studies on this topic [8, 11]. Mitchell et al. [17] from
New Zealand found a higher prevalence of wheezing in children from families with low socioeconomical status. There was no relationship between socioeconomical status and asthma diagnosis or bronchial hyperresponsiveness. A study performed by the Italian Studies on Respiratory Disorders in Childhood and the Environment group in Italy found that urbanisation and socioeconomical status had little impact on the prevalence of wheezing or asthma, but might influence the management of asthma [18]. The severity of asthma in children was associated with low socioeconomical class in a German study [19], which confirms the present findings of a higher risk of hospitalisation for asthma in the group with psychosocial problems, thereby indicating poorer control of asthma.

This study confirms most of the medical factors previously associated with asthma. Hay fever as a 
marker of atopic disposition is a risk factor for asthma $[3,20]$. Allergic reactions to food can create serious problems in a small number of children. The more unspecific question about "any reaction to food", which includes different intolerance reactions, was associated with asthma [6]. The finding of more than three episodes of fever during the last year as an independent risk factor is probably linked to episodes of bronchial obstruction initiated by common viral infections [7, 21], which make the fever episodes memorable to the parents. It is well known that some children who develop asthma later in life are more sensitive to upper respiratory tract infections, and that they will have more serious symptoms than other children when they are ill [20].

Recent studies have indicated that early orofaecal infections, such as hepatitis A, as well as many siblings, especially older ones, may have a certain protective effect against the development of atopic diseases [22]. However, asthma, as it is defined in the present study, is not equivalent to allergy, and further studies are required to explore these theories. This is underlined by a new Norwegian study showing that day care attendance is associated with a higher frequency of childhood asthma [23], while others have shown that an early introduction to day care attendance can protect against the development of allergy [13].

It is interesting that a number of risk factors that have been significant in other studies could not be confirmed in the present study. Previously, it has been suggested that males are more vulnerable than females in younger age groups [3], that breastfeeding would protect against asthma [9], that the early use of antibiotics [5] and having few siblings [11] would increase the risk for the development of asthma. These, and the importance of smoking during pregnancy or at home [10], were not confirmed.

This study shows a cumulative prevalence of bronchial asthma among children aged 4-5 yrs, of $8.7 \%$, which is similar to previous Norwegian studies. Socioeconomic factors seem to be associated with the development of childhood asthma, in addition to previously known risk factors, such as atopy, food reactions and asthma inheritance.

\section{References}

1. Nystad W, Magnus P, Roksund O, Svidal B, Hetlevik $O$. The prevalence of respiratory symptoms and asthma among school children in three different areas of Norway. Pediatr Allergy Immunol 1997; 8: 35-40.

2. Magnus P, Jaakkola JJ. Secular trend in the occurrence of asthma among children and young adults: critical appraisal of repeated cross sectional surveys. BMJ 1997; 314: 1795-1799.

3. Lundback B. Epidemiology of rhinitis and asthma. Clin Exp Allergy 1998; 28: Suppl. 2, 3-10.

4. Wickens K, Pearce N, Siebers R, et al. Indoor environment, atopy and the risk of the asthma in children in New Zealand. Pediatr Allergy Immunol 1999; 10: 199-208.
5. Wickens K, Pearce N, Crane J, Beasley R. Antibiotic use in early childhood and the development of asthma. Clin Exp Allergy 1999; 29: 766-771.

6. Wright AL, Holberg CJ, Taussig LM, Martinez FD. Relationship of infant feeding to recurrent wheezing at age 6 years. Arch Pediatr Adolesc Med 1995; 149: 758 763.

7. Martinez FD. Viral infections and the development of asthma. Am J Respir Crit Care Med 1995; 151: 1644 1648.

8. Horwood LJ, Fergusson DM, Shannon FT. Social and familial factors in the development of early childhood asthma. Pediatrics 1985; 75: 859-868.

9. Oddy WH, Holt PG, Sly PD, et al. Association between breast feeding and asthma in 6 year old children: findings of a prospective birth cohort study. BMJ 1999; 319: 815-819.

10. Stein RT, Holberg CJ, Sherrill D, et al. Influence of parental smoking on respiratory symptoms during the first decade of life: the Tucson Children's Respiratory Study. Am J Epidemiol 1999; 149: 1030-1037.

11. Wickens KL, Crane J, Kemp TJ, et al. Family size, infections, and asthma prevalence in New Zealand children. Epidemiology 1999; 10: 699-705.

12. Finnvold JE, Nordhagen R, Schalm A. Astma blant barn skjevt sosialt fordelt. [Asthma in childhood with skewed social distribution]. Samfunnsspeilet 1997; 2: $10-15$.

13. Kramer U, Heinrich J, Wjst M, Wichmann HE. Age of entry to day nursery and allergy in later childhood. Lancet 1999; 353: 450-454.

14. Nystad W, Skrondal A, Magnus P. Day care attendance, recurrent respiratory tract infections and asthma. Int J Epidemiol 1999; 28: 882-887.

15. Hosmer DW, Lemeshow S. Applied Logistic Regression. John Wiley and Sons, New York, 1989.

16. Nystad W, Magnus P, Soyseth V. Forekomsten av astma blant skolebarn i Norge i perioden 1985-94. [The prevalence of asthma in school children in Norway during the period 1985-94]. Tidsskr Nor Laegeforen 1997; 117: 644-647.

17. Mitchell EA, Stewart AW, Pattemore PK, Asher MI, Harrison AC, Rea HH. Socioeconomic status in childhood asthma. Int $J$ Epidemiol 1989; 18: 888-890.

18. Anonymous. Asthma and respiratory symptoms in 6-7 yr old Italian children: gender, latitude, urbanization and socioeconomic factors. SIDRIA (Italian Studies on Respiratory Disorders in Childhood and the Environment). Eur Respir J 1997; 10: 1780-1786.

19. Mielck A, Reitmeir P, Wjst M. Severity of childhood asthma by socioeconomic status. Int J Epidemiol 1996; 25: 388-393.

20. Martinez FD, Wright AL, Taussig LM, Holberg CJ, Halonen M, Morgan WJ. Asthma and wheezing in the first six years of life. The Group Health Medical Associates. N Engl J Med 1995; 332: 133-138.

21. Nafstad P, Magnus P, Jaakkola JJ. Early respiratory infections and childhood asthma. Pediatrics 2000; 106: E38.

22. Johnston SL, Openshaw PJM. The protective effect of childhood infections. BMJ 2001; 322: 376-377.

23. Nystad WSA, Magnus P. Barnehage, infeksjoner og astma. [Day care attendance, infections and asthma]. Tidsskr Nor Laegeforen 2001; 121: 282-286. 